\title{
EXPERIMENTAL STUDY OF SINGLE-ROTOR UAV ON DROPLET DEPOSITION DISTRIBUTION IN SOYBEAN FIELD
}

\author{
ZHANG, K. F. - ZHANG, Z. - ZHANG, Y. H. - LI, H.* \\ College of Mechanical and Electrical Engineering, Henan Agricultural University, Zhengzhou \\ 450002, China \\ *Corresponding author \\ e-mail: chungbuk@163.com
}

(Received 20 $0^{\text {th }}$ May 2019; accepted 28 ${ }^{\text {th }}$ Aug 2019)

\begin{abstract}
It is particularly important to improve soybean yield and its management in the middle and late stage. Therefore, in view of the difficult problems of traditional field management machines, such as difficult operation, seedling pressing and so on. In this paper, the following two aspects of experimental research are carried out: the wind field distribution characteristics of single-rotor Unmanned Aerial Vehicle (UAV); the contrast test of the deposition distribution of different types of UAV. The spray test of single-rotor UAV in the middle and late stage of soybean was carried out to optimize the operation parameters of UAV. The experimental data is provided to improving the application of field management and UAV application technology in the middle and late stages of soybean production. The results show that the droplets of single rotor UAV can reach the lower part of soybean canopy, and the density of droplets can be more than $15 / \mathrm{cm} 2$. The data also provides technical support for experimental study.

Keywords: plant protection, unmanned aerial vehicle, Huang-Huai-Hai area, wind field, droplet density
\end{abstract}

\section{Introduction}

Agriculture is the foundation of China's economic construction and development, and the guarantee of the country's prosperity and strength. For a long time, soybean has been loved by people all over the world because of its high quality edible oil, excellent plant protein and many kinds of active substances which are beneficial to the human body (Yang, 2010; Chen et al., 2017 ${ }^{\text {a }}$ Zhang et al., 2015). Soybean, as a feed crop, food crop, oil crop, cash crop and vegetable crop, has a large cultivation area and yield in the United States, Brazil and other countries. With a long planting history, China is one of the major producers of soybean (Zhang, 2007).

In recent years, the domestic demand for soybean has increased year by year, but the soybean output in our country is far from satisfying the domestic demand, which leads to a situation where we have to rely on a large number of imported foreign soybeans. This situation directly threatens the food security of China (Yang et al., 2008; Chen et al., 2017 ${ }^{\mathrm{b}}$ ).

Figure 1 shows the statistics of Chinese soybean imports from 2012 to 2017. According to the statistics of the General Administration of Customs from January to December 2017, the total amount of imported soybeans has reached $9.55 \times 10^{7} \mathrm{t}$, an increase of $1.16 \times 10^{7} \mathrm{t}$ compared to $8.391 \times 10^{7} \mathrm{t}$ in 2016.The data of the National Bureau of Statistics shows that the total output of legumes (soybeans and other miscellaneous beans) in China is about $1.9 \times 10^{7} \mathrm{t}$, which is the direct result of the $6.52 \times 105 \mathrm{hm}^{2}$ increase in soybean planting area (Lou et al., 2017).

At present, the largest soybean production area in China includes three provinces in northeast China, followed by the summer soybean production area in Huang-Huai-Hai region, where the annual soybean production accounts for about $30 \%$ of the total 
soybean production in China. Compared with the large-scale self-propelled spraying machinery and the operation mode of agricultural plant protection aircraft in the three provinces of northeast China, soybean plant protection in Huang-Huai-Hai area is mainly carried out by manual sprayer and backpack motor sprayer. This limits the operation of large-scale plant protection machinery because of the characteristics of land management mode and small plot in Huang-Huai-Hai area. At the same time, the development of pesticide application technology in our country, especially the development of pesticide application machinery, is lagging behind in the worsening of diseases and insect pests (Liu et al., 2015; Chen et al.,2017c; Qin et al., 2014). There are still many problems in the prevention and control of disease and pests, and the demand for soybean in China has been high all the time, but the soybean output cannot meet the change of this situation, which results in the need to import a large number of foreign soybeans, posing a direct threat to food security in our country. $86 \%$ soybean demand depends on imports and the imports in 2017 set a high record again, which is a further increase trend.

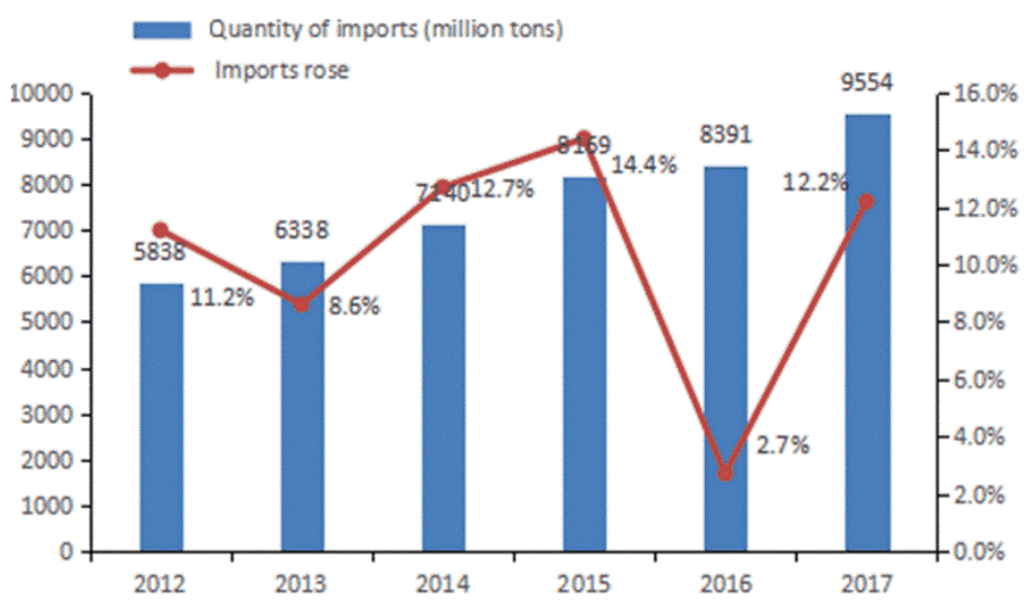

Figure 1. Soybean import quantity statistics

The development of UAV for plant protection in recent years has offered a new idea for soybean field plant protection (Jin et al., 2016). Single-rotor UAV has been widely used in agricultural plant protection because of its single wind field, uniform spraying, strong penetration, etc. (Gong and Fu, 2008; Guo et al., 2014; Xu et al., 2017). In order to solve the problems existing in soybean field management at the present stage, single rotor plant protection UAV was used in the field experiment in the middle and late stage of soybean, in order to solve the difficulty of traditional field management machine, which enter the soybean field in the middle and late stage of soybean, whose ridge was sealed. It solves pressing seedlings and other difficult problems, too. The field operation parameters of UAV were optimized, and the experimental data and technical support were provided for the application of field management and UAV application technology in the middle and late stages of soybean production. So wind field tests for a singlerotor UAV were carried out in this paper.

The influence of operation speed, flight height and the addition of flight control auxiliary equipment on droplets deposition was analyzed, and the optimal operation parameters in different periods were obtained. Providing field operation and the 
optimization of key operation parameters for the applicability of plant protection unmanned aerial vehicle in soybean, are to solve the problem of landing for traditional spraying way during the middle and late stage.

\section{Wind field tests for single-rotor UAV}

\section{Material}

The test model is the electric single-rotor UAV (Mercury one), which is powered by a high-performance polymer lithium battery and is equipped with a remote control and a matching spray system, as is shown in Figure 2.The spray rod is adjustable which is installed with two fan-shaped spray nozzles with spray width of generally $7 \mathrm{~m}$, different types of sprayers can be changed according to the use of different pesticides. Meanwhile, in order to measure wind speed, wind direction and temperature and humidity, we need to prepare multichannel anemometer, computer, temperature and humidity tester (CEM DT-615), portable anemometer (LB-SD2) and timer.

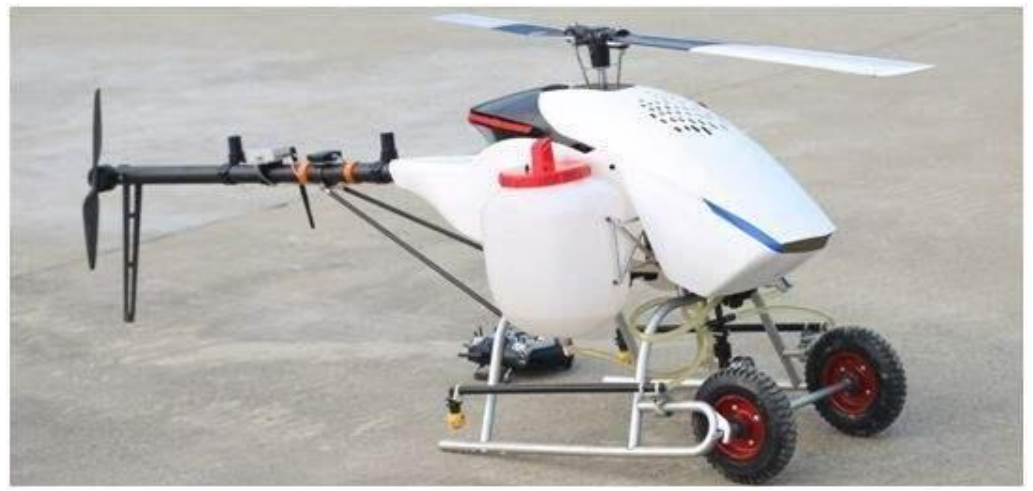

Figure 2. Anelectric single-rotor UAV (Mercury one)

\section{Test method}

The experiment was carried out in an experiment plot of Henan Agricultural University. During the test, the wind direction and wind speed were measured with a multichannel anemometer and a handheld anemometer (LB-SD2) at the test site. A temperature and humidity tester (CEM DT-615) is used to record the temperature of the test site and the time required for the test is recorded by a timer. The schematic diagram of the working principle is shown in Figure 3.

The wind field test of single-rotor plant UAV needs to determine the boundary of wind field. The multichannel anemometer and the handheld anemometer were used to find the boundary of the wind field (wind speed less than $0.2 \mathrm{~m} / \mathrm{s}$ ), and the boundary of the wind field was recorded.

Before the wind field test was carried out, it was necessary to determine the measurement point of the test, which started from the vertical bottom of the rotor of the UAV (as shown in the Fig. 3). Below the rotor of the plant protection UAV was the "O" point of the center. The wind field was measured all the way to the boundary, which was measured with a tape ruler every 0.5 meters. And eight directions were measured in one torus. In the direction of height $\mathrm{Z}$, the height of soybean at branching stage and podsetting stage were recorded at $0.5 \mathrm{~m}, 1 \mathrm{~m}, 1.5 \mathrm{~m}$ and $2 \mathrm{~m}$ respectively. The median 
volume diameter $\left(\mathrm{D}_{50}\right)$ of agriculture flat-fan nozzle were used (Zhao et al., 2009).The spraying dose was $450 \mathrm{~L} / \mathrm{ha}$. The speed of the UAV was $5 \mathrm{~m} / \mathrm{s}$. The experiments had been replicated for three times.

Through the wind field test, the best flying altitude range of the single-rotor UAV was obtained. Within the same scope, the single-rotor plant UAV can achieve better spray drop deposition distribution compared to the multi-rotor UAVs.

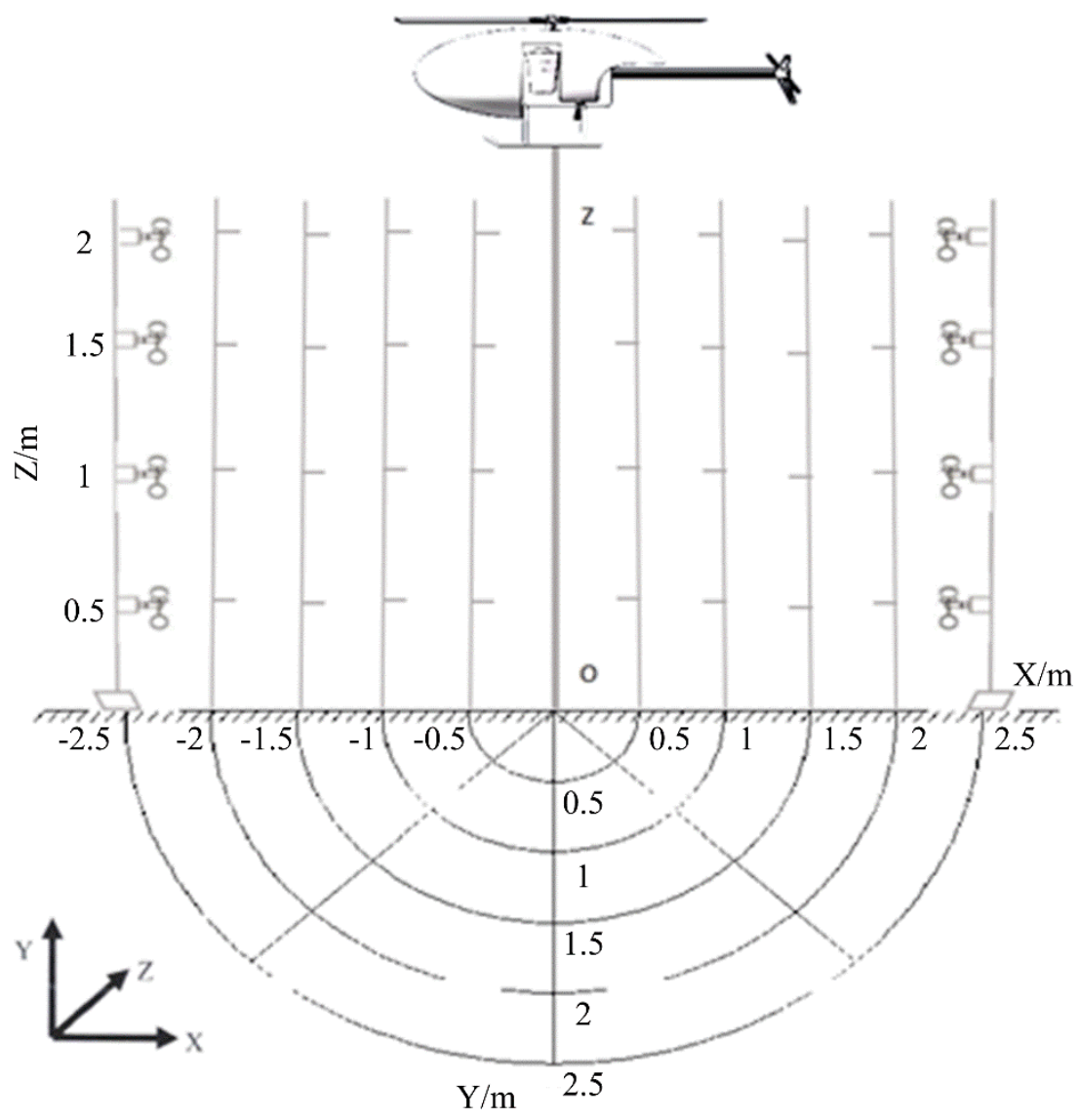

Figure 3. Wind farm test layout

\section{Results and discussion}

In the wind field test, the temperature is $17.5^{\circ} \mathrm{C}$, the wind speed is $0.2 \sim 1.5 \mathrm{~m} / \mathrm{s}$ and the wind direction are southwest. During the experiment, the head of the drone was placed westward, and the fixed height of the drone was adjusted to $2.88 \mathrm{~m}$. The measured data of each measurement point in the test are shown in Table 1.

As shown in Figure 4, the wind speed distribution of $0.5 \mathrm{~m}, 1 \mathrm{~m}, 1.5 \mathrm{~m}$ and $2 \mathrm{~m}$ from the plant canopy below the rotor shows that the distribution of wind field at different altitudes is basically similar. With the decrease of distance from the plant canopy, the wind speed is smaller. The decrease of the velocity below the center of the rotor is the fastest. From the wind field test data of Table 1 and Figure 4 and the simulation diagram of actual wind field test, it can be seen that the wind speed increases gradually with the increase of the center distance of the rotor axis in the range of rotor span of the single-rotor UAV. Outside the wingspan of the rotor, the wind speed decreases 
gradually. In the rotor height direction, the wind speed increases first and then declines with the rise of the distance from the rotor. The trend is that the maximum wind speed is in the range of $1.5 \mathrm{~m}$ below the rotor, and the wind speed reaches about $12 \mathrm{~m} / \mathrm{s}$.

Table 1. Wind field test data

\begin{tabular}{|c|c|c|c|c|c|c|c|c|c|c|c|c|c|c|c|}
\hline $\mathbf{X} / \mathbf{m}$ & $\mathrm{Y} / \mathrm{m}$ & $\mathrm{Z} / \mathbf{m}$ & $\begin{array}{l}\text { Wind } \\
(\mathrm{m} / \mathrm{s})\end{array}$ & $\mathrm{X} / \mathrm{m}$ & $\mathrm{Y} / \mathrm{m}$ & $\mathrm{Z} / \mathrm{m}$ & $\begin{array}{l}\text { Wind } \\
(\mathrm{m} / \mathrm{s})\end{array}$ & $\mathbf{X} / \mathbf{m}$ & $\mathrm{Y} / \mathbf{m}$ & $\mathrm{Z} / \mathrm{m}$ & $\begin{array}{l}\text { Wind } \\
(\mathrm{m} / \mathrm{s})\end{array}$ & $\mathrm{X} / \mathrm{m}$ & $\mathrm{Y} / \mathrm{m}$ & $\mathrm{Z} / \mathrm{m}$ & $\begin{array}{l}\text { Wind } \\
(\mathrm{m} / \mathrm{s})\end{array}$ \\
\hline 0.0 & -2.5 & 1.0 & 0.3 & 0.0 & -2.5 & 1.5 & 1.5 & \begin{tabular}{|l|l}
0.0 \\
\end{tabular} & -2.5 & 2.0 & 1.9 & 0.0 & -2.5 & 2.5 & 2.1 \\
\hline-0.5 & -0.5 & 1.0 & 5.7 & -0.5 & -0.5 & 1.5 & 7.8 & -0.5 & -0.5 & 2.0 & 9.8 & -0.5 & -0.5 & 2.5 & 11.0 \\
\hline-1.0 & -1.0 & 1.0 & 7.1 & -1.0 & -1.0 & 1.5 & 10.5 & -1.0 & -1.0 & 2.0 & 9.9 & -1.0 & -1.0 & 2.5 & .4 \\
\hline-1.5 & 1.5 & 1.0 & 70 & -1.5 & -1.5 & 1.5 & 40 & -1.5 & -1.5 & 2.0 & 2.1 & -1.5 & -1.5 & 2.5 & 2.8 \\
\hline-2.0 & -2.0 & 1.0 & 3.5 & -2.0 & -2.0 & 1.5 & 1.0 & -2.0 & -2.0 & 2.0 & 0.8 & -2.0 & -2.0 & 2.5 & 0.5 \\
\hline-2.5 & -2.5 & 1.0 & 1.9 & -2.5 & -2.5 & 1.5 & 0.0 & -2.5 & -2.5 & 2.0 & 0.0 & -2.5 & -2.5 & 2.5 & 0.3 \\
\hline-0.5 & 0.0 & 1.0 & 6.4 & -0.5 & 0.0 & 1.5 & 7.1 & -0.5 & 0.0 & 2.0 & 9.4 & -0.5 & 0.0 & 2.5 & 11.0 \\
\hline-1.0 & 0.0 & 1.0 & 6.8 & -1.0 & 0.0 & 1.5 & 8.2 & -1.0 & \begin{tabular}{|l|l} 
\\
0.0
\end{tabular} & 2.0 & 9.4 & -1.0 & 0.0 & 2.5 & 11.3 \\
\hline-1.5 & 0.0 & 1.0 & 7.7 & -1.5 & 0.0 & 1.5 & 4.9 & -1.5 & 0.0 & 2.0 & 3.1 & -1.5 & 0.0 & 2.5 & 1.9 \\
\hline-2.0 & 0.0 & 1.0 & 7.3 & -2.0 & 0.0 & 1.5 & 5.2 & -2.0 & \begin{tabular}{|l|l} 
\\
0.0
\end{tabular} & 2.0 & 4.3 & -2.0 & 0.0 & 2.5 & .9 \\
\hline 2.5 & 0.0 & 1.0 & 2.2 & 2.5 & 0.0 & 1.5 & 0.5 & 2.5 & 0.0 & 2.0 & 0.8 & 2.5 & 0.0 & 2.5 & 1.7 \\
\hline-0.5 & 0.5 & 1.0 & 5.7 & -0. & 0.5 & 1.5 & 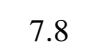 & -0.5 & 0.5 & 2.0 & & -0.5 & 0.5 & 2.5 & 11.0 \\
\hline-1.0 & 1.0 & 1.0 & 7.1 & -1.0 & 1.0 & 1.5 & 10.5 & -1.0 & 1.0 & 2.0 & 9. & -1.0 & 1.0 & 2.5 & .4 \\
\hline-1.5 & 1.5 & 1.0 & 7.0 & -1.5 & 1.5 & 1.5 & 4.0 & -1.5 & 1.5 & 2.0 & 2.1 & -1.5 & 1.5 & 2.5 & .8 \\
\hline-2.0 & 2.0 & 1.0 & 3.5 & -2.0 & 2.0 & 1.5 & 1.0 & -2.0 & 2.0 & 2.0 & 0.8 & -2.0 & 2.0 & 2.5 & 0.5 \\
\hline-2.5 & 2.5 & 1.0 & 1.9 & -2.5 & 3.5 & 1.5 & 0.0 & -2.5 & 2.5 & 2.0 & 0.0 & -2.5 & 2.5 & 2.5 & 0.3 \\
\hline 0.0 & 0.5 & 1.0 & 4.0 & 0.0 & 0.5 & 1.5 & 45 & 0.0 & 0.5 & 2.0 & 71 & 0.0 & 0.5 & 2.5 & .1 \\
\hline 0.0 & 1.0 & 1.0 & 7.5 & 0.0 & 1.0 & 1.5 & 7.1 & 0.0 & 1.0 & 2.0 & 5.2 & 0.0 & 1.0 & 2.5 & .6 \\
\hline 0.0 & 1.5 & 1.0 & 3.3 & 0.0 & 1.5 & 1.5 & 0 & 0.0 & 1.5 & 2.0 & 0.0 & 0.0 & 1.5 & 2.5 & 8 \\
\hline 0.0 & 2.0 & 1.0 & 2.8 & 0. & 2.0 & 1.5 & 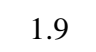 & 0.0 & 2.0 & 2.0 & 1.5 & 0.0 & 2.0 & 2.5 & .4 \\
\hline 0.0 & 2.5 & 1.0 & 2. & 0 & 2.5 & 1. & & 0.0 & 2.5 & 2.0 & & 0.0 & 2.5 & 2.5 & 3 \\
\hline 0.5 & 0.5 & 1.0 & 5. & 0. & 0.5 & 1.5 & & 0.5 & 0.5 & 2.0 & , & 0.5 & 0.5 & 2.5 & 11.0 \\
\hline 1.0 & 1.0 & 1.0 & 7.1 & 1.0 & 1.0 & 1.5 & 10.5 & 1.0 & 1.0 & 2.0 & 9. & 1.0 & 1.0 & 2.5 & 9.4 \\
\hline 1.5 & 1.5 & 1.0 & 7.0 & 1.5 & 1.5 & 1.5 & 4.0 & 1.5 & 1.5 & 2.0 & 2.1 & 1.5 & 1.5 & 2.5 & 2.8 \\
\hline 2.0 & 2.0 & 1.0 & 3.5 & 2.0 & 2.0 & 1.5 & 1.0 & 2.0 & 2.0 & 2.0 & 0.8 & 2.0 & 2.0 & 2.5 & 0.5 \\
\hline 2.5 & 2.5 & 1.0 & 1.9 & 2.5 & 2.5 & 1.5 & 0.0 & 2.5 & 2.5 & 2.0 & 0.0 & 2.5 & 2.5 & 2.5 & 0.3 \\
\hline 0.5 & 0.0 & 1.0 & 6.4 & 0.5 & 0.0 & 1.5 & 7. & 0.5 & \begin{tabular}{|l|l} 
\\
\end{tabular} & 2.0 & 9.4 & 0.5 & 0.0 & 2.5 & 11.0 \\
\hline 1.0 & 0.0 & 1.0 & 6. & 1. & 0.0 & 1. & 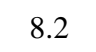 & 1.0 & \begin{tabular}{|l|l} 
\\
0.0
\end{tabular} & 2.0 & 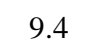 & 1.0 & 0.0 & 2.5 & 11.3 \\
\hline 1.5 & 0.0 & 1.0 & 7. & 1 & 0.0 & 1.5 & & 1.5 & $\begin{array}{l}0.0 \\
\end{array}$ & 2.0 & 3 & 1.5 & 0.0 & 2.5 & 1.9 \\
\hline 2.0 & 0.0 & 1.0 & 7.3 & 2.0 & 0.0 & 1. & & 2.0 & 0.0 & 2.0 & & 0 & 0.0 & 2.5 & 2.9 \\
\hline 2.5 & 0.0 & 1.0 & 2.2 & 2.5 & 0.0 & 1.5 & 0.5 & 2.5 & $\mid 0.0$ & 2.0 & 0. & 2.5 & 0.0 & 2.5 & 1.7 \\
\hline 0.5 & -0.5 & 1.0 & 5.7 & 0.5 & -0.5 & 1.5 & 7.8 & 0.5 & -0.5 & 2.0 & 9.8 & 0.5 & -0.5 & 2.5 & 11.0 \\
\hline 1.0 & -1.0 & 1.0 & 7.1 & 1.0 & -1.0 & 1.5 & 10.5 & 1.0 & -1.0 & 2.0 & 9.9 & 1.0 & -1.0 & 2.5 & 9.4 \\
\hline 1.5 & -1.5 & 1.0 & 7.0 & 1.5 & -1.5 & 1.5 & 4.0 & 1.5 & -1.5 & 2.0 & 2.1 & 1.5 & -1.5 & 2.5 & 2.8 \\
\hline 2.0 & -2.0 & 1.0 & 3.5 & 2.0 & -2.0 & 1.5 & 1.0 & 2.0 & -2.0 & 2.0 & 0.8 & 2.0 & -2.0 & 2.5 & 0.5 \\
\hline 2.5 & -2.5 & 1.0 & 1.9 & 2.5 & -2.5 & 1.5 & 0.0 & 2.5 & -2.5 & 2.0 & 0.0 & 2.5 & -2.5 & 2.5 & 0.3 \\
\hline
\end{tabular}

It can be seen from Figure 5 that the wind speed gradually decreases with the decrease of the rotor height within the span of the rotor, and the wind speed is affected by the plant canopy effect about $0.5 \mathrm{~m}$ away from the plant canopy, and the wind speed decreases gradually from the center of the rotor to the outside. Outside the wingspan, the wind velocity in the direction of height is not obviously weakened. 


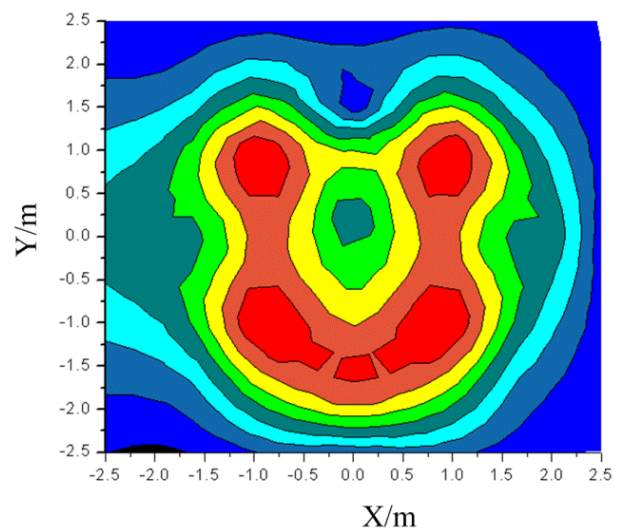

(a) $\mathrm{Z}=0.5 \mathrm{~m}$

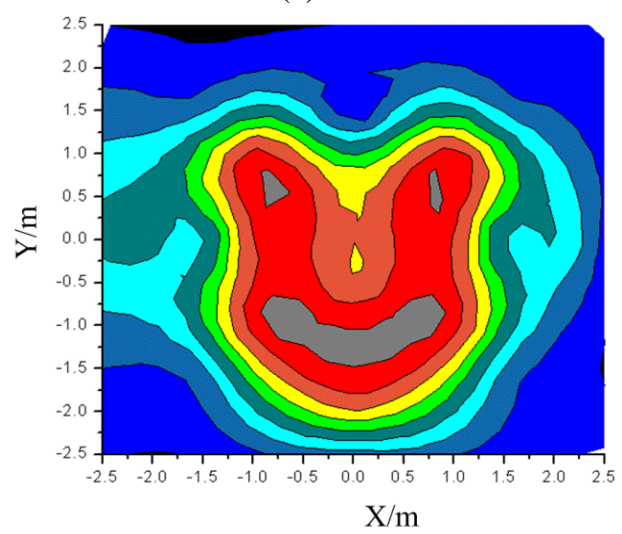

(c) $\mathrm{Z}=1.5 \mathrm{~m}$
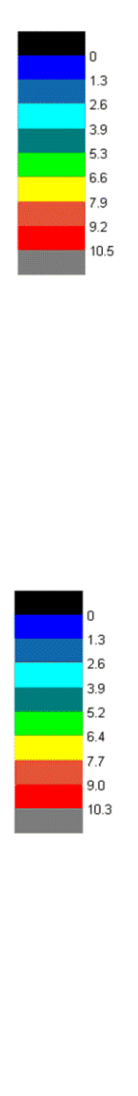

Figure 4. Different heights wind farm test plan. (Note: $Z$ is the height from the plant canopy)

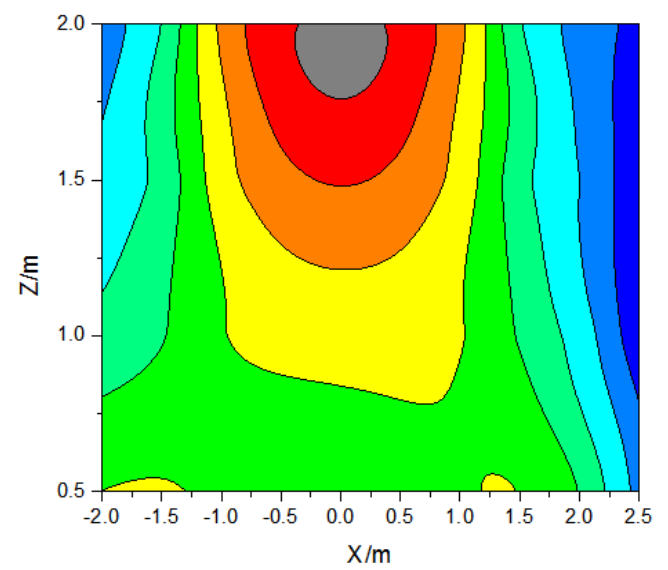

Figure 5. Wind farm distribution map in the vertical direction of the rotor

Taking the plant canopy as the reference and the rotor axis of the single-rotor UAV as the center, the vertical wind field were measured vertically up the plant canopy, and the vertical wind field data were obtained. The following conclusions are drawn from the analysis:

1. At the same height from the plant canopy, the wind velocity value is positively correlated with the axis distance within the wingspan range, and the wind 
speed increases gradually with the increase of the distance, and decreases gradually beyond the wingspan range until the boundary of the wind field.

2. In the direction of altitude, the value of wind velocity is positively correlated with the height off the plant canopy.

3. The maximum wind speed is $1-2.5 \mathrm{~m}$ above the plant canopy, and the maximum wind speed is $12.9 \mathrm{~m} / \mathrm{s}$. Therefore, in the field operation, the flying altitude of the single-rotor UAV is best within this range, which is favorable for the airflow and droplets to reach the bottom of the canopy.

4. Under the influence of plant canopy effect, turbulence will appear in the wind field below $1 \mathrm{~m}$, and there is no definite rule.

\section{Spray deposition contrast test}

In order to test the difference between single-rotor plant UAV and multi-rotor plant protection drone, different models were selected to carry out. The spray tests of S40 single rotor, M23 electric four rotors and M8A electric eight rotor plant protection UAV were carried out in soybean field, and the spray drop deposition distribution of different types of UAV was compared and analyzed.

\section{Materials and methods}

\section{Experimental laboratory materials and equipment}

In order to compare the effects of droplet deposition with Mercury 1 electric singlerotor UAV, three different UAV were prepared for soybean field experiments, as shown in Figure 6. The parameters of the three UAV are shown in Table 2.

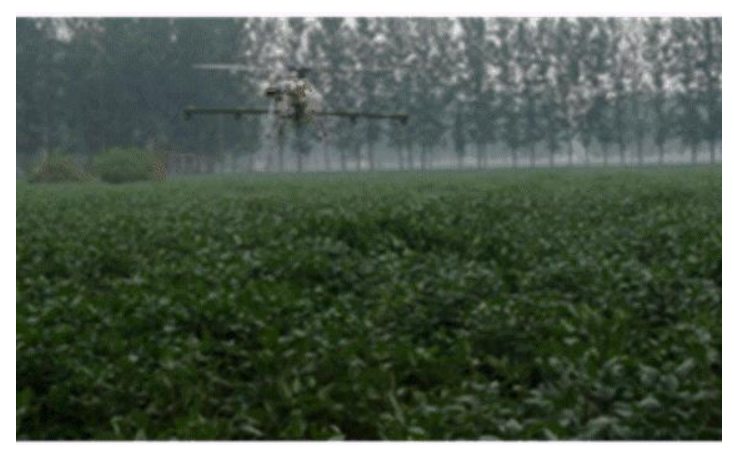

(a) $\mathrm{S} 40$

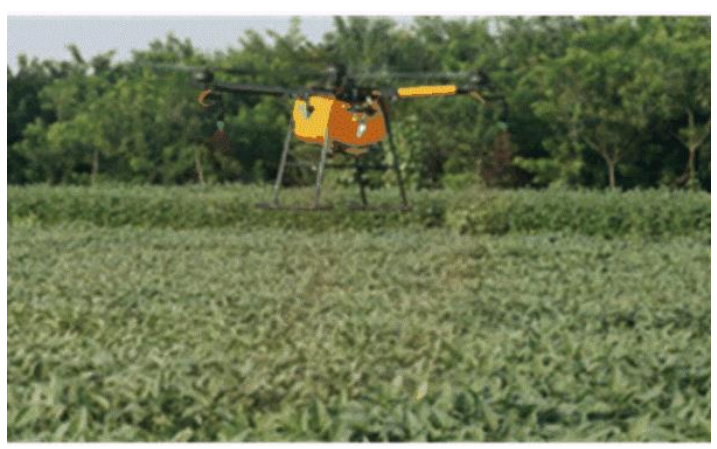

(b) M23

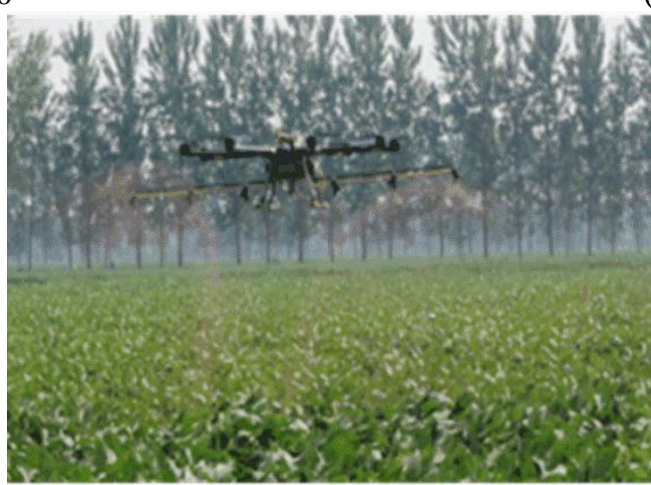

(c) M8A

Figure 6. Three kinds of UAV 
Table 2. Main parameters

\begin{tabular}{c|c|c|c}
\hline Type & S40 & M23 & M8A \\
\hline Size $(\mathrm{mm} \times \mathrm{mm} \times \mathrm{mm})$ & $2165 \times 2400 \times 720$ & $1318 \times 1318 \times 685$ & $1360 \times 1360 \times 650$ \\
Maximum $(\mathrm{load} / \mathrm{L})$ & 20 & 10 & 10 \\
Flight $\mathrm{speed}(\mathrm{m} / \mathrm{s})$ & 5 & 5 & 5 \\
Flight height $(\mathrm{m})$ & $1-3$ & $1-3$ & $1-3$ \\
Spraying width $(\mathrm{m})$ & $4-7$ & $4-6$ & $4-5$ \\
Number of sprinklers & 5 & 4 & 6 \\
\hline
\end{tabular}

\section{Reagent preparation}

The analytical instrument is micro-spectrophotometer with a maximum absorption wavelength of $508 \mathrm{~nm}$. First, prepare labeling group, use $500 \mathrm{ml}$ volumetric flask to prepare $1 \mathrm{~g} / \mathrm{L}$ liquid containing carmine, extract $50 \mathrm{ul}, 150 \mathrm{ul}, 250 \mathrm{ul}, 350 \mathrm{ul}, 450 \mathrm{ul}$, $550 \mathrm{ul}, 650 \mathrm{ul}, 750 \mathrm{ul}, 850 \mathrm{ul}, 950 \mathrm{ul}$ solution with pipette to be placed in $10 \mathrm{ml}$ volumetric flask, balance, measure the absorbance, repeat each test three times to obtain average standard curve. In order to indicate deposition quantity with ratio of carmine, curve model of absorbance versus carmine solution concentration was established. Determination coefficient was calculated by linear regression curve fitting as $\mathrm{R}^{2}=0.997$. As measurement of deposition quantity needs test of dilution concentration, relationship between carmine solution concentration and absorbance was obtained via variable conversion:

$$
C=0.0363 A-0.0016
$$

where $C$ is mass concentration $(\mathrm{g} / \mathrm{L})$ of the carmine solution and $A$ is absorbance of the carmine solution.

\section{Test method}

The experiment was carried out in Liangshan county demonstration base of "Research on high-yield and high-efficiency mechanization production technology and supporting equipment of soybean". The experiment was carried out in the middle and late stages of soybean growth. The row spacing and plant height of soybean in the experimental field were $40 \mathrm{~cm}$ and $90 \mathrm{~cm}$ respectively. The spray liquid used in this experiment is $4 \mathrm{~g} / \mathrm{L}$ rouge aqueous solution, and the droplet collection card is used to collect the droplet. In the field experiment of soybean, three groups of spray tests were compared in the range of spraying in the same plant protection unmanned aerial vehicle (UAV) operation, and 8 points were continuously arranged at $1.2 \mathrm{~m}$ interval in the transverse direction, and 8 points were arranged continuously in the same plant protection unmanned aerial vehicle (UAV) operation. Longitudinally: corresponding transverse, control test every 5 meters, continuous arrangement of 3 each collecting point, the upper, middle and lower layers are arranged to collect droplets acquisition card (Fig. 7). Every time the plant protection drone flies along the set axis, in order to stabilize the test operation, the aircraft hovers and takes off at $10 \mathrm{~m}$ in the acquisition point, and stops operation after $10 \mathrm{~min}$ away from the acquisition point. The temperature and humidity meter and wind speed and wind direction meter were used to measure and record the environmental parameters during the plant protection unmanned aerial vehicle operation. 


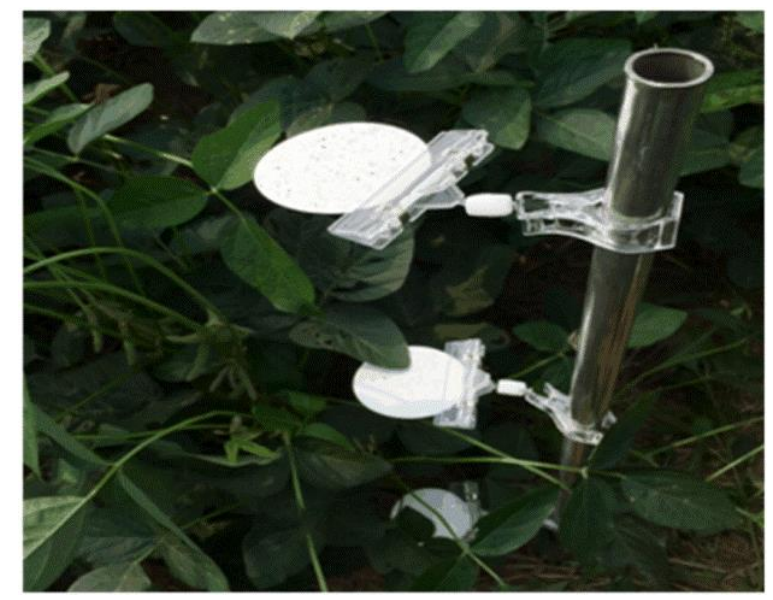

Figure 7. Collection point layout

\section{Results and discussion}

\section{Test results of droplet deposition distribution}

The data of droplet deposition and density of droplet deposition are shown in Table 3.

Table 3. Mean value of droplet deposition

\begin{tabular}{|c|c|c|c|c|c|c|}
\hline \multirow[b]{2}{*}{ Number } & \multicolumn{2}{|c|}{ S40 Electric single rotor } & \multicolumn{2}{|c|}{ M23 Electric four rotor } & \multicolumn{2}{|c|}{ M8A Electric eight rotor } \\
\hline & $\begin{array}{c}\text { Deposits } \\
\left(\mathrm{cm}^{2}\right)\end{array}$ & $\begin{array}{c}\text { Deposition } \\
\left(\mu \mathrm{L} / \mathrm{cm}^{2}\right)\end{array}$ & $\begin{array}{c}\text { Deposits } \\
\left(\mathrm{cm}^{2}\right)\end{array}$ & $\begin{array}{c}\text { Deposition } \\
\left(\mu \mathrm{L} / \mathbf{c m}^{2}\right)\end{array}$ & $\begin{array}{c}\text { Deposits } \\
\left(\mathbf{c m}^{2}\right)\end{array}$ & $\begin{array}{c}\begin{array}{c}\text { Deposition } \\
\left(\mu \mathrm{L} / \mathrm{cm}^{2}\right)\end{array} \\
\end{array}$ \\
\hline $\mathrm{A} 0-1$ & 39.2 & 0.210 & 23.0 & 0.047 & 18.5 & 0.036 \\
\hline $\mathrm{A} 0-2$ & 62.0 & 0.122 & 21.4 & 0.018 & 18.0 & 0.016 \\
\hline $\mathrm{A} 0-3$ & 11.8 & 0.027 & 5.2 & 0.003 & 5.8 & 0.004 \\
\hline A $1-1$ & 27.1 & 0.125 & 15.7 & 0.012 & 41.1 & 0.067 \\
\hline A1-2 & 29.7 & 0.526 & 21.8 & 0.022 & 45.9 & 0.072 \\
\hline A $1-3$ & 20.4 & 0.049 & 11.9 & 0.010 & 15.4 & 0.026 \\
\hline A2-1 & 44.5 & 0.330 & 41.1 & 0.115 & 61.7 & 0.977 \\
\hline A $2-2$ & 45.3 & 0.149 & 43.4 & 0.097 & 58.6 & 0.264 \\
\hline A2-3 & 9.5 & 0.030 & 13.8 & 0.012 & 21.6 & 0.047 \\
\hline A3-1 & 35.1 & 0.302 & 21.3 & 0.035 & 40.2 & 0.104 \\
\hline A3-2 & 17.2 & 0.207 & 42.6 & 0.066 & 78.7 & 0.236 \\
\hline A3-3 & 6.9 & 0.014 & 8.7 & 0.006 & 29.5 & 0.084 \\
\hline A4-1 & 37.2 & 0.281 & 35.1 & 0.055 & 16.2 & 0.027 \\
\hline A4-2 & 28.4 & 0.068 & 13.6 & 0.017 & 26.8 & 0.033 \\
\hline A4-3 & 8.8 & 0.049 & 7.3 & 0.011 & 10.5 & 0.022 \\
\hline A5-1 & 55.1 & 0.595 & 51.7 & 0.105 & 63.1 & 0.211 \\
\hline A5-2 & 41.4 & 0.278 & 64.4 & 0.143 & 55.0 & 0.217 \\
\hline A5-3 & 8.7 & 0.043 & 29.7 & 0.053 & 12.5 & 0.028 \\
\hline A6-1 & 53.2 & 0.406 & 26.8 & 0.040 & 50.4 & 0.109 \\
\hline A6-2 & 23.8 & 0.086 & 36.8 & 0.035 & 35.2 & 0.101 \\
\hline A6-3 & 4.3 & 0.016 & 10.8 & 0.014 & 10.8 & 0.026 \\
\hline A7-1 & 29.9 & 0.194 & 24.4 & 0.068 & 22.9 & 0.044 \\
\hline A7-2 & 24.6 & 0.105 & 67.9 & 0.179 & 32.1 & 0.125 \\
\hline A7-3 & 6.0 & 0.014 & 34.6 & 0.046 & 10.3 & 0.017 \\
\hline
\end{tabular}




\section{Analysis of droplet distribution uniformity}

As shown in Figure 8, the three UAV were all carried out under the best operating parameters. It can be seen from Figure 8, the deposition distribution of droplets in each collecting point is different under different operating parameters. The deposition amount and uniformity of each collecting point are relatively good on the whole, and the droplets of each collecting point are relatively good. The coefficient of variation is $37.37 \%$, the coefficient of variation is $69.34 \%$, and the coefficient of variation is $110.88 \%$. The coefficient of variation reflects the droplet deposition uniformity of the UAV, and the results show that the droplet distribution uniformity of the single rotor UAV is better than that of the multi-rotor UAV as a whole.

It also can be concluded that the drift on the right side is larger than that on the left side, and the drift is smaller when the operating speed is $5 \mathrm{~m} / \mathrm{s}$. It can be seen from that there is little difference in droplets deposition data collected from at different operating parameters. Under different operating parameters, it can be concluded that the singlerotor UAV has a single and stable downwind field and less ground loss and drift.

The wind field of S40 single-rotor plant UAV is relatively stable. It has a strong penetrating and a better droplet deposition and uniformity. The six nozzles of M8A eight-rotor UAV are arranged under the fuselage, and there is disturbance between the wind field, so the distribution of turbulence is not uniform. The M23 four-rotor drone with one nozzle under each rotor, has enough atomization and less deposition.

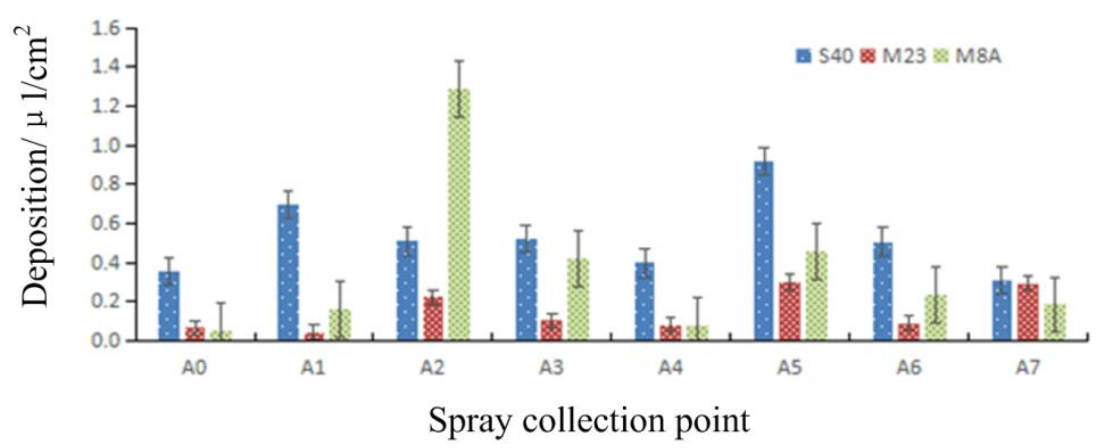

Figure 8. Plant protection UAV deposition layout

\section{Comparative analysis of penetration of fog droplets}

As can be seen from Figure 8, the density of droplets in each sampling point of soybean canopy can reach $15 / \mathrm{cm}^{2}$. As shown in Figure 9, the distribution of droplets in the upper, middle and lower canopy of three UAV can be visualized to show the penetration of droplets in different UAVs.

Figure 9 shows when the S40, M23, and M8A UAVs are operated, droplets can reach the lower layer of the soybean blade. The density of droplets deposited in the lower layers decreased gradually. The density of droplets in the middle layer of soybean decreased by $14.75 \%$ compared with that in the upper layer, and that in the lower layer decreased by $71.85 \%$ compared with that in the middle layer. During the spraying operation with M23 electric four-rotor UAV, the droplet density of the middle blade is higher than that of the upper layer and the lower layer, and the deposition density of the middle layer is higher than that of the lower layer. The density of droplets in the lower 
layer was $60.77 \%$ less than that in the middle layer. During the spraying operation with the M8A electric eight-rotor UAV, the droplet deposition density of the middle layer blade was $10.27 \%$ higher than that of the upper layer blade, and the lower layer was $66.67 \%$ lower than that of the middle layer.

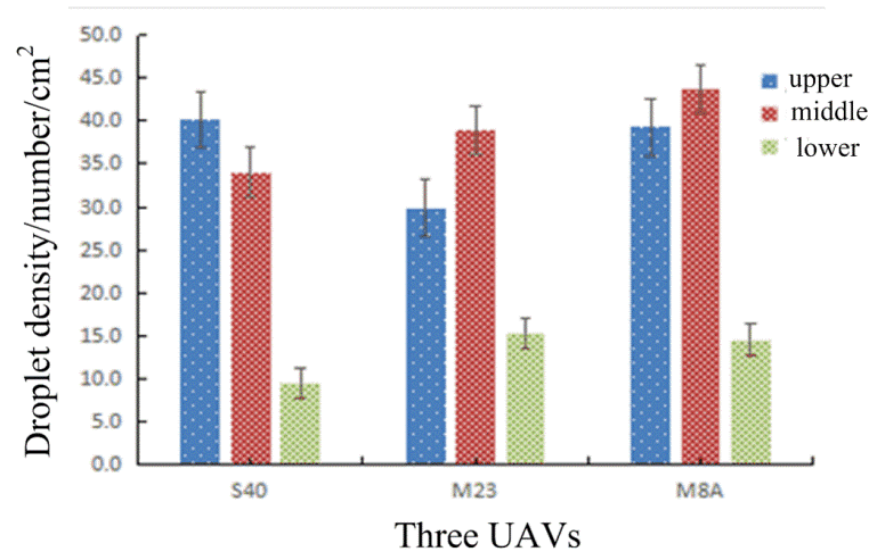

Figure 9. Droplet distribution in soybean canopy

\section{Conclusions}

The main parameters of S40 electric single rotor, M23 electric four rotor and M8A electric eight rotor UAV are briefly introduced. The spray experiments in the soybean pod period are carried out with these models.

Under different operating parameters, height and velocity have significant influence on the deposition and distribution of droplets. As the wind field of the single-rotor plant protection unmanned aerial vehicle is single, droplets can reach the bottom of the soybean canopy under different working parameters. At different speeds and heights, the deposition amount and distribution uniformity of droplets are different. The deposition density of upper, middle and lower canopy droplets of soybean has certain regularity. The results of droplet deposition show that the droplets of single rotor and multi-rotor UAV can reach the lower part of soybean canopy, and the density of droplets can be more than $15 / \mathrm{cm}^{2}$. The single rotor UAV has a single wind field, uniform distribution and strong penetration.

Acknowledgements. The authors would like to thank the National Soybean Industry Technical System Foundation of China (Contract No. CARS-04), the Natural Science Foundation of Henan Province (Contract No. 162300410155) and the Natural Science Foundation of China (Contract No. 31501213) for their supports of this work. Furthermore, the authors would sincerely thank the reviewers for their very professional suggestions on this study.

\section{REFERENCES}

[1] Chen, S. D., Lan, Y. B., Li, J. Y., Xu, X. J., Wang, Z. G., Peng, B. (2017a): Evaluation and test of effective spraying amplitude of plant protection UAV during aerial spraying. Journal of Agricultural Engineering 33(7): 82-90. 
[2] Chen, S. D., Lan, Y. B., Li, J. Y., Zhou, Z. Y., Liu, A. M., Xu, X. J. (2017b): Comparison of effects of aerial spraying and artificial spraying on rice application. - Journal of South China Agricultural University 38(4): 103-109.

[3] Chen, S. D., Lan, Y. B., Zhou, Z.Y., Liao, J., Zhu, Q.Y. (2017c): Effects of spray parameters of small plant protection UAV on droplet deposition in orange canopy. Journal of South China Agricultural University 38(5): 97-102.

[4] Gong, Y., Fu, X. M. (2008): Aeronautical application technology in modern agriculture. Agricultural Equipment Technology 34(6): 26-29.

[5] Guo, Y. W., Yuan, H. Z., He, X. K., Shao, Z. R. (2014): General situation and prospect analysis of agricultural aviation plant protection development in China. - China Journal of Plant Protection 34(10): 78-82.

[6] Jin, X., Dong, X., Yan, X. J., Yan, H. R. (2016): Design and test of target spray system for 3WGZ-500 sprayer. - Journal of Agricultural Machinery 47(7): 21-27.

[7] Liu, K. X. (2015): Development status of agricultural aviation industry in Russia, Japan and South Korea. - Age Agricultural Machinery 42(7): 169.

[8] Lou, S. Y., Xue, X. Y., Gu, W., Cui, L. F., Zhou, Q. Q., Wang, X. (2017): Research status and trend of Agricultural Plant Protection Unmanned aerial vehicle. - Agricultural Mechanization Research 39(12): 1-6, 31.

[9] Qin, W. C., Xue, X. Y., Zhou, L. X., Zhang, S. C., Sun, Z., Kong, W., Wang, B. K. (2014): Effect of spray parameters of unmanned helicopter on droplet deposition distribution in maize canopy. - Journal of Agricultural Engineering 30(5): 50-56.

[10] Xu, Y., Xiao, Y. J., Liu, J. H., Zhou, J. S., Song, X. Q., Dai, X. H. (2017): Impact of drones on agricultural modernization. - Agricultural Services 34(16): 43.

[11] Yang, H. Q. (2010): Analysis and discussion on the current situation of soybean industry in China. - China Seed Industry 4: 18-20.

[12] Yang, W. Y., Yong, T. W., Ren, W. J. (2008): Develop industry soybean, revitalize soybean industry. - Soybean Science 27(1): 1-7.

[13] Zhang, F. S. (2007): Study on the Effect of Plant Protection on Grain Production Safety in China. - Fujian Agricultural and Forestry University, Fujian.

[14] Zhang, S. C., Xue, X. Y., Qin, W. C., Xun, Z., Ding, S. M., Zhou, L. X. (2015): Simulation and experiment of N-3 type agricultural unmanned helicopter's airborne application drift. - Journal of Agricultural Engineering 31(3): 87-93.

[15] Zhao, H., Song, J. L., Zeng, A. J., He, X. K. (2009): Correlations between dynamic surface tension and droplet diameter. - Transactions of the Chinese Society for Agricultural Machinery 40(8): 74-79. 